\title{
Uma oportunidade histórica
}

\author{
CARLOS EDUARDO MOREIRA FERREIRA
}

$\mathrm{D}$ ETERMINAÇÃO E PRAGMATISMO são posturas que se consolidam entre os brasileiros em razão do processo de estabilização da economia, da abertura comercial e da integração internacional dos mercados. A nossa sociedade - em particular os empresários - está amadurecendo rapidamente num contexto de mudanças aceleradas, em que os acertos criam oportunidades reais de desenvolvimento e em que a memória de experiências recentes e traumáticas é o referencial obrigatório para uma necessária cultura da prudência.

Os tradicionais ciclos de euforia ou pessimismo que infernizaram a vida dos brasileiros nas últimas décadas são substituídos pela atenção constante às chances e aos riscos de um período histórico de transição mundial. Aos poucos a palavra crise é erradicada do vocabulário, não por força de um decreto, mas porque as perspectivas do novo cenário se sobrepõem a velhos paradigmas. Tal aspecto não evita as oscilações de percurso, mas garante um mínimo de segurança na trajetória para o crescimento econômico e o desenvolvimento social.

As exportações brasileiras são um termômetro dessa evidência. O déficit da balança comercial, por exemplo, que foi de US\$ 5,53 bilhões em 1996, não pode ser visto apenas como um comportamento medíocre das nossas vendas ao exterior. Deve ser encarado, sobretudo, pelo enorme potencial de crescimento que revela. Em vez de assustar, pode servir de alerta para combater os entraves que precisam ser eliminados e, ao mesmo tempo, estimular a agressividade que o país precisa demonstrar em relação à conquista do mercado mundial.

Não basta que alguns setores da nossa economia sejam competitivos internacionalmente, como o são materiais de transporte, café, calçados e couro, máquinas e instrumentos mecânicos - setores que lideraram, nessa ordem, as exportações do ano passado. É preciso que toda a produção tenha a marca da competitividade, o que implica a eliminação do Custo Brasil por meio da aprovação das reformas constitucionais, da aceleração das privatizações, do incentivo aos investimentos estrangeiros e da alocação maciça de recursos em tecnologia, treinamento, educação e saúde.

Temos cacife para tanto. As exportações, que somaram US\$ 47,7 bilhões no ano passado e cresceram 2,67\% com relação a 1995, demonstram uma tendência adequada na qual os produtos manufaturados ocupam $60,31 \%$ da receita total. Se somarmos ainda os semimanufaturados, constataremos que a indústria é responsável por $76,67 \%$ das vendas ao exterior.

Por isso, temos insistido junto aos investidores estrangeiros sobre a necessidade de se incrementar a produção brasileira de maior valor agregado, para 
podermos aumentar nossa competitividade no mercado internacional, superando de vez o ciclo da predominância das matérias-primas.

Dimensionar os investimentos para empresas que tenham produção em escala internacional, e não apenas direcioná-las para o mercado interno, é o desafio. Não podemos mais nos restringir a aceitar a partilha do mercado dentro das nossas fronteiras sem uma reciprocidade além de seus limites. Esse enfoque é fundamental quando levamos em conta que os investimentos externos no Brasil, em 1996, atingiram US\$ 33 bilhões. Destes, US\$ 9,4 bilhões foram investimentos diretos na produção, que poderão chegar a US\$ 15 bilhões em 97.

Temos apresentado tal enfoque aos visitantes estrangeiros que aportam na Fiesp - entre eles, por exemplo, personalidades do porte do presidente Jacques Chirac, da França, do primeiro-ministro José María Aznar, da Espanha, e do presidente da Toyota e do Keidanren (Federação das Organizações Econômicas do Japão), Shoichiro Toyoda. Procuramos demonstrar a quantos nos procuram que o Brasil se tornou um dos mais atraentes pólos para investimentos do mundo. A infra-estrutura e o parque industrial instalados garantem o suporte necessário para um salto na produção. Das 500 maiores empresas do mundo, quase 400 estão presentes no Brasil. Somos o décimo produtor de carros do planeta e o oitavo produtor mundial de aço bruto.

O aumento de $6,88 \%$ das importações - que chegaram a US\$ 53,2 bilhões demonstra o incremento do poder aquisitivo do mercado interno. Temos uma população de 156 milhões de habitantes, e só no estado de São Paulo concentram-se 34 milhões de pessoas. A população economicamente ativa é calculada em 74 milhões e, com o Plano Real, estima-se que mais de 30 milhões de brasileiros, que se encontravam à margem do consumo, entraram no mercado.

Depois da visita do presidente Chirac à América Latina e de suas declarações sobre a importância do subcontinente, a própria Charlene Barshefsky, subsecretária de Comércio dos Estados Unidos, retificou declarações anteriores e reconheceu publicamente a força do bloco econômico do qual o Brasil é o país líder. Ela destacou que o Mercosul é a maior economia da América Latina - PIB de US\$ 1 trilhão e população de 200 milhões de habitantes. É dentro dessa realidade que nosso país precisa aumentar suas exportações de manufaturados, ter acesso aos mercados mais desenvolvidos e competir com volume e alta qualidade dos produtos.

A partir da abertura comercial, a indústria brasileira ajustou-se às novas condições do mercado globalizado. Estamos prontos para crescer em bases estáveis e queremos parceiros e sócios. Desejamos um ambiente no qual o setor privado assuma rapidamente a liderança do processo econômico, o que já começa a ocorrer. Nos últimos cinco anos o empresariado deu uma formidável demonstração de competência para enfrentar desafios e superar adversidades. Hoje, podemos falar numa nova estrutura industrial brasileira (predominantemente moderna, ágil, competitiva, preparada, enfim, para enfrentar os desafios da 
globalização. A mudança deu-se ao longo de um processo marcado por iniciativas como reestruturação interna, com reflexos, inclusive, no emprego; redefinição de linhas de produção; racionalização do trabalho; requalificação da mão-deobra; investimento na qualidade; busca de financiamentos externos; atualização de produtos; venda de ativos; maior utilização de insumos importados.

Podemos dizer que a disposição para atualizar o sistema produtivo já é parte da nossa cultura empresarial, e essa é uma tarefa em que nos empenhamos com o claro objetivo de recuperar o tempo perdido. As medidas de ajuste foram acompanhadas por um aumento substancial nos investimentos. Segundo dados oficiais, a indústria brasileira obteve ganhos de produtividade da ordem de $45 \%$, nos últimos seis anos.

Estimativas sobre intenções de investimentos indicam que, até o ano 2000, empresas de diversos setores estarão implementando mais de 1.500 projetos, com inversões calculados em US\$ 156 bilhões. Desse total, US\$ 57 bilhões, ou seja, cerca de um terço, serão destinados à infra-estrutura, beneficiando áreas de saneamento básico, geração e transmissão de energia, construção e expansão de ferrovias, portos e aeroportos, ampliação dos serviços de telecomunicações.

O desenvolvimento é o caminho mais eficiente para eliminar as disparidades regionais que ainda persistem no Brasil. A integração mais forte do Nordeste na economia nacional e sua inserção no mercado global, por exemplo, passa necessariamente pela implantação de novas empresas na região. E esse é um processo que já está em andamento, indicando que o desequilíbrio econômico pode chegar ao fim, com a inauguração de uma fase de maior distribuição de riquezas e justiça social. Segundo o presidente Fernando Henrique Cardoso, só nos primeiros meses deste ano foram aplicados no Nordeste R\$ 200 milhões para a conclusão de 50 obras inacabadas. Enquanto isso, o Banco do Nordeste anuncia que R\$ 2,5 bilhões foram aplicados em $1996 \mathrm{em}$ projetos que abriram mais de 500 mil oportunidades de empregos na região.

A esperança não pode, entretanto, se deixar contaminar pelo ufanismo, como acontecia no passado. Um dos desafios estratégicos mais importantes é saber negociar com nossos parceiros do exterior. Segundo estudo do Ministério das Relações Exteriores, a abertura da economia do Brasil à concorrência externa não teve a contrapartida de melhores condições de acesso da produção nacional, por exemplo, aos mercados da União Européia e dos Estados Unidos. Ao contrário, aumentaram os níveis de incidência tarifária sobre diversos produtos brasileiros. Persistem barreiras, em particular de natureza não-tarifária, sobre as exportações de certos produtos industrializados, como têxteis, calçados, ferro e aço. Além disso, nossos produtos agrícolas e alimentares enfrentam mecanismos protecionistas resultantes da política para a agricultura do continente europeu.

O embaixador José Botafogo Gonçalves, subsecretário geral de Assuntos de Integração Econômica e de Comércio Exterior do Itamaraty, já advertiu que a retirada de barreiras interpostas pelos EUA e União Européia a produtos brasi- 
leiros é pré-condição para negociar qualquer futuro acordo. O Brasil não assume posições isoladas. Fala escudado no Mercosul, especialmente agora em que há pressões norte-americanas para acelerar o processo de integração por meio da ALCA - Área de Livre Comércio das Américas.

O Brasil propõe que o avanço do processo de abertura comercial se desenvolva de forma planejada e segura. Já aprendemos a lição de como não se deve proceder quando se trata de abrir as fronteiras econômicas sem o devido cuidado, sem que os setores produtivos estejam preparados para um ritmo de abertura que deve ser civilizado e nunca selvagem. Por isso, é conveniente negociar em bloco, pois, quanto mais a economia brasileira crescer e mais aumentar a nossa capacidade de exportar, mais conflitos surgirão, não só com os Estados Unidos, mas com outros países como os da União Européia, Canadá ou Japão.

Temos que valorizar nossas conquistas. De janeiro a dezembro do ano passado, as exportações brasileiras para os demais países do Mercosul foram de US\$ 7,3 bilhões, que significam 15,3\% do total das nossas vendas ao exterior e um incremento de 18,7\% com relação a 1995. Entre 1991, ano de criação do bloco regional, e 1996, a corrente de comércio do Brasil com Argentina, Paraguai e Uruguai mais que triplicou, passando de US\$ 4,6 bilhões para algo próximo dos US\$ 15 bilhões.

É importante destacar que as vitórias do governo e da sociedade estão sendo consolidadas dentro de um regime democrático, com plena liberdade política, respeito ao direitos individuais e aos princípios da livre iniciativa. Vivemos, portanto, um momento privilegiado da nossa história nacional. O Brasil não pode perder esta chance para dar o grande salto, tantas vezes ensaiado, rumo ao desenvolvimento econômico e à construção de uma nação mais equilibrada, com uma sociedade mais justa.

Carlos Eduardo Moreira Ferreira é advogado, empresário e presidente da Federação e do Centro das Indústrias do Estado de São Paulo. 